\title{
A diversidade na escola e as novas demandas para o trabalho docente ${ }^{1}$
}

Diversity in school and new requirements for teaching work

Gustavo Bruno Bicalho Gonçalves*

Universidade Federal de Minas Gerais

Resumo $\quad \mathrm{O}$ artigo parte dos princípios da justiça social e da justiça escolar, que fundamentam as políticas públicas voltadas para a atenção à diversidade na educação e analisa seu objetivo manifesto de contribuir para a promoçã̃o da igualdade. Com base nas declarações fornecidas pelos professores participantes na segunda fase da pesquisa "Trabalho docente na educação básica no Brasil", analisamos os efeitos dessas políticas, tal como expressado na contradição experienciada pelos professores no trabalho, quando tratam de adaptar o princípio da igualdade à atenção à diversidade. Observa-se que esta contradição reflete-se em novas cargas de trabalho e dificuldade para encontrar sentido no trabalho realizado.

PALABRAS-CHAVE: Trabalho docente, Diversidade, Saúde e trabalho.

Abstract This article begins with a discussion of the principles of social justice and school justice that underlies public policies for diversity in schools, and it examines the stated goal that aims at contributing to promotion of equality. Based on statements provided by the teachers participating in the second phase of the research project "Teaching Work in Basic Education in Brazil", we analyze the effects of these policies as expressed in the contradiction experienced by teachers at work, when they try to adapt the principle of equality to the attention to diversity. We observe that this contradiction leads to new workloads and makes it difficult for teachers to find meaning in their work.

KEYWORDS: Teaching work, Diversity, Work and health. 


\section{Introdução}

Do ponto de vista histórico-social, o Brasil viveu importantes mudanças no modo de regulação do seu sistema educativo ao longo dos anos 90 . Estas mudanças basaram-se na transferência de uma parte do poder de atores internos ao sistema escola a certos atores externos. Ao mesmo tempo, novas ferramentas de avaliação e comparação internacionais, tais como o PISA, ganharam terreno e, através de mecanismos de classificação de países e de escolas, a comparação e a concorrência tornaram-se um meio de regulação dos sistemas educacionais cada vez mais presente. No Brasil, também foram criados novos mecanismos de avaliação com o objetivo de monitorar o desempenho do sistema escolar, tal como o Índice de Desenvolvimento da Educação Básica (IDEB²). Paralelamente, defende-se os ideais de uma escola mais justa e democrática, que ajude a combater as desigualdades sociais em vez de reproduzí-las. Como consequência, observa-se um aumento das tensões entre a inclusão, a equidade e a performance dos sistemas, com importantes reflexos sobre as condições em que se exerce, atualmente, o trabalho docente na escola básica.

De um ponto de vista teórico, como afirma Dubet (2008), se por um lado a educação permite recompor desigualdades e ajudar a constituir uma sociedade mais igualitária, ela também está na base do argumento pelo qual justificamos as desigualdades em nossa sociedade. O conceito de igualdade pode fundamentar uma noção de justiça escolar meritocrática, baseada na idéia de uma competição justa entre alunos que teriam condições de partida similares. Se é no sistema educacional que os jovens aprendem a conviver com o diferente e têm acesso à uma socialização secundária baseada em uma cultura comum, também é nela que se diferenciam, e é a partir dela que se distribuem os lugares na hierarquia social. A educação pretende, portanto, ser inclusiva, mas é também seletiva; pretende basear-se na equidade, mas baseia-se na performance; pretende valorizar a cooperação, mas dá lugar à competição; e pretende respeitar a igualdade formal de todas as pessoas, mas precisa dar a cada um conforme suas necessidades. São esses dilemas constantes com os quais lida o sistema escolar.

O objetivo atribuído ao trabalho docente vêm se modificando em função da emergência de novas políticas educacionais voltadas, para o atendimento à diversidade. Nossa hipótese é que aumentam as pressões sobre o professor, posto que cabe a ele lidar com o paradoxo da abertura à diversidade, e ao mesmo tempo o controle dos mecanismos de avaliações sistêmicas. Para melhor entender essas tensões apresentaremos alguns autores que propõem uma discussão sobre o conceito de igualdade como princípio orientador da escola republicana. Posteriormente, serão examinados os conceitos mais específicos que embasam as políticas focalizadas de redistribuição dos bens escolares e o reconhecimento das especificidades culturais dos grupos alvo dessas políticas. Finalmente, nos referiremos ao contexto político da emergência dessas políticas na Europa e na América Latina, para poder assim retomar nossa hipótese de partida, analisando novos limites e contradições do trabalho docente, bem como possíbilidades de atuação que a ele se abrem. 


\section{Promessas de igualdade da escola democrática}

Pode-se dizer que, atualmente, há um amplo consenso mundial sobre a importância de os países disporem de um sistema educacional aberto à diferença e capaz de combater a desigualdade. As agências das Nações Unidas, bem como grande número de governos nacionais defendem a expansão dos sistemas educacionais como um mecanismo eficaz de promoção da justiça social. Entretanto, muitos autores têm questionado os problemas intrínsecos associados à promessa de uma crescente igualdade social por meio da expansão do acesso e permanência no sistema educacional. Gostaríamos, portanto, de examinar estas contradições sem pretender resolvê-las aqui, mas apenas para apontar sua articulação com o debate sobre o atendimento à diversidade que faremos mais adiante. Começaremos pelos aportes da filosofia política (MASSCHELEIN; SIMONS, 2011). Posteriormente, analisaremos questões colocadas a partir de estudos de corte antropológico (BRUNO, 2011), para por fim examinarmos as contribuições da sociologia da educação (DUBET; DURU-BELLAT; VÉRÉTOUT, 2010).

O trabalho de Masschelein e Simons (2011) apoia-se no do filósofo político francês Jacques Rancière, particularmente sobre as questões da democracia, da igualdade e do papel público da educação. Rancière critica intelectuais tais como Bourdieu e Milner por tomarem a desigualdade como um pressuposto e, por isso, sempre provarem sua existência e a redescobrirem. Para Rancière, ao se conceber a escola como uma máquina de reproduzir a desigualdade social, tal como Bourdieu, ou ao se conceber a escola como um instrumento para reduzir a desigualdade, como Milner, o efeito continuaria sendo o mesmo: a manutenção de uma distância entre a igualdade futura e a desigualdade atual. A existência da igualdade, como uma promessa a ser cumprida, permite justificar a permanência do ignorante em seu lugar na ordem social, atribuído segundo sua natureza ou suas capacidades. Desta maneira, a configuração do sistema educativo contribui à configuração de uma ordem social desigual, naturalizando as desigualdades e as racionalizando. A ordem social ideal seria, portanto, aquela justificada pelas diferenças, resultantes das qualificações escolares e das desigualdades sociais (RANCIÈRE apud MASSCHELEIN e SIMONS, 2011). Contrapondo-se a esta perspectiva hegemônica, Rancière (2002) relata a história de Joseph Jacotot, cuja experiência como o professor sugere uma forma inédita de lidar com a diferença. Jacotot afirma que a igualdade não se constitui em nenhum critério nem meta para transformar a sociedade, posto que ela pode ser o ponto de partida, axioma ou hipótese prática que fomenta o pensamento, o experimento e a invencão. Sua lição sobre a emancipação passa pela afirmação de uma igualdade intelectual que se coloca em prática através do simples mecanismo de eliminar a explicação do professor como mediação necessária para a aquisição do conhecimento. Este mecanismo permite criar uma relação de igualdade entre alunos e professor, completamente inusitada se considerada a forma tradicional de organização da escola, baseada na assimetria entre professor e aluno e na capacidade do primeiro de explicar ao segundo e iniciá-lo no saber. 
Deixemos por um momento a experiência de Jacotot e passemos a uma segunda experiência que coloca em questão a relação entre escola e produção da igualdade relatada por Lúcia Bruno (2011). Para a autora, o sistema educacional brasileiro, tal como concebido e tal como viabilizado por meio da lógica burocrática do Ministério da Educação e secretarias estaduais e municipais de educação entra em contradição com lógicas societais completamente díspares quando propõe uma educação escolarindígena. A autora analisa a relação de ensino-aprendizagem entre os guarani-mbya na aldeia de Paraty-Mirim e descreve uma horizontalidade na forma de circulação dos saberes que seria estranha à forma como tradicionalmente vem se organizando o trabalho escolar nas aldeias. A autora destaca que, nas chamadas sociedades modernas ocidentais, o saber configura poder e, ao justificar desigualdades em uma organização social extremamente hierárquica, viabiliza a dominação de uns poucos sobre muitos. Por sua vez, nas sociedades indígenas brasileiras estudadas pela autora, o saber teria como objetivo"o viver bem, alcançar a felicidade de si e dos parentes, para que se queira permanecer vivo nesta Terra cheia de perigos e ameaças" (p. 658), logo sua prática pedagógica se baseia em uma pedagogia na qual a participação na sociedade é seu traço característico, e em interações em que seria fundamental adentrar o ponto de vista do outro, e não a promoção individual. A autora conclui que o nosso modelo de escola não é adequado para ser oferecido aos povos indígenas, do mesmo modo que ela não acredita que suas sociedades tenham modelos que possam ser transpostos para a nossa.

Nas duas experiências, até agora evocadas, a eliminação da concepção do diverso, do outro como alguém de fora a ser incluído, reconhece um lugar de igual para a alteridade, e forja os preceitos de uma escola inclusiva que não se coloca desta forma, posto que o outro, o diferente, não é um suposto desigual, não é um estranho, mas parte constituinte da multiplicidade na qual estamos todos inseridos. Mas este pode ser um princípio para a organização do trabalho pedagógico em nossas sociedades?

Uma terceira aproximação ao problema da relação entre escola e igualdade analisa a centralidade do diploma na atribuição de lugares na hierarquia social. A partir de uma comparação internacional, envolvendo os países da OCDE, Dubet, Duru-Bellat e Vérétout (2010), constataram que quanto maior a influência do diploma na determinação do destino social do indivíduo, maior a contribuição da escola no desenvolvimento das desigualdades sociais e maior as desigualdades escolares. Dito de outra forma, as desigualdades escolares tendem a ser mais fortes em sociedades onde o poder do diploma de determinar a posição social do indivíduo é maior, posto que as famílias atuam em função deste dado para otimizar as chances de suas crianças se diferenciarem da massa. Ora, são justamente as famílias mais favorecidas que tem os melhores recursos para brigarem pelos melhores diplomas, em um jogo que tende, portanto, a perpetuar seus privilégios. Dubet, Duru-Bellat e Vérétout vêm assim a confirmar, através de suas recentes pesquisas de campo que abarcam diferentes países, mais uma vez, o papel da escola na reprodução das desigualdades. 
Na convergência destas três reflexões, que denominaremos a "política", a "antropológica" e a "sociológica", é possível enxergar importantes limites para se pensar a escola como simples promotora da igualdade. Eis aqui nossa questão: se as desigualdades de talentos, inteligência, interesses e necessidades são a premissa para pensar o sistema educacional e também o que se verifica constantemente nas medições e avaliações sistêmicas, como esperar que ele promova a justiça social por meio da redução das desigualdades?

\section{Grupos emergentes e novas regulações}

Como estratégia para a redução das desigualdades, os movimentos sociais apresentam suas demandas por acesso e permanência no sistema de ensino, pautando-se pela busca do reconhecimento da diferença. Segundo Nancy Fraser (2001), a luta pelo reconhecimento é a forma pela qual grupos privados de participar em pé de igualdade na vida social, portanto, desfavorecidos no acesso à educação, têm procurado garantir seu direito. Coletivos sociais como os movimentos de luta pela terra, movimentos indígenas, quilombolas, movimentos étinicos-raciais e de gênero engendram ações e políticas para compensar sua falta ou desvantagem na participação social. São reinvindicações por um reconhecimento que deve estar acompanhado da compreensão dos mecanismos pelos quais as diferenças se convertem em relações de dominação cultural e de desfavorecimento sócioeconômico.

É, no sentido de atuar na reversão dessas relações de desfavorecimento, permitindo reconhecimento e visibilidade social para esses grupos marginalizados, que o universo da educação apresenta-se como um universo privilegiado de atuação ${ }^{3}$. Considera-se que a possibilidade de lutar pelo reconhecimento das especificidades desses grupos encontra-se não só no âmbito das lutas pelo direito à escola, mas também dentro da escola, que deve adaptar-se para dar as mesmas chances de aprendizado para todos ${ }^{4}$. Em função dessas pressões, a escola transforma-se, portanto, em um importante território de disputa por políticas de correção das desigualdades.

A multiplicação de programas e políticas voltadas para a correção de problemas de desigualdade escolar, na Europa, foi objeto de um estudo concluído

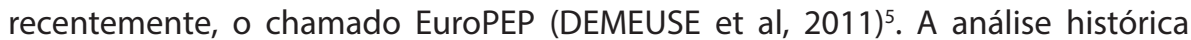
da evolução destas políticas no espaço europeu, revela que as primeiras políticas de educação prioritária, na Europa, tiveram lugar na década de sessenta. Segundo Frandji e Rochex (2011) estas políticas se expressaram de formas diferentes em diferentes países. Dos oito países analisados pelo estudo, a maioria passou por reformulações em suas políticas na história recente. Essas reformulações responderam a distintos modelos: primeiro o modelo da compensanção, logo o modelo da luta contra a exclusão, para finalmente chegar ao modelo hoje, difundido de adaptação à diversidade. Este modelo é identificado como a "terceira idade" das politicas de educação prioritária, que visam a redução das desigualdades. Para esses autores as políticas atuais são caracterizadas pela retórica da diversidade e maximização dos potenciais de cada um, assumindo objetivos cada vez mais 
individualizantes, mudando o quadro de referência das políticas escolares para uma abordagem na qual é o sistema educativo que deve adaptar-se à diversidade dos indivíduos, e não mais os diferentes contextos sociais que devem adaptar-se ao sistema educativo. Dito de outro modo, a agenda dessas políticas é a adaptação à diversidade pensadas não mais como desigualdades: deve-se oferecer à cada criança a possibilidade de desenvolver-se segundo seu potencial e, ao mesmo tempo, regular os efeitos da competição, administrar os riscos e zelar pela coesão social. Se levarmos em conta que, de um ponto de vista ético, essa retórica é difícil de contestar, não é difícil de compreender que nos encontramos face a um novo ponto de tensão que remete, segundo nosso modo de ver, às condições filosóficas, antropológicas e sociais contraditórias às que já aludimos.

A diversificação das políticas educacionais e sua convergência para um discurso sobre a diversidade reflete-se, no Brasil, na criação da SECAD Secretaria de Educação Continuada, Alfabetização e Diversidade, pelo Ministério da Educação em 2004, cujo objetivo é contribuir para a redução das desigualdades educacionais, por meio da ampliação do acesso à educação e programas específicos voltados para públicos minoritários. Esta estrutura governamental responde à demanda de grupos, que não se sentiam contemplados em políticas educacionais de caráter universal (GOMES, 2011) e denotam a intenção de produzir justiça escolar, por meio de medidas compensatórias e focalizadas, visando dar reconhecimento a grupos historicamente desfavorecidos na distribuição dos bens sociais e compensar as desigualdades por meio de políticas de ação afirmativa.

A partir da evolução dessas políticas na Europa e no Brasil ${ }^{6}$, nota-se que o conceito de justiça escolar transita de uma concepção mais universalista para um progressivo reconhecimento da diversidade dos públicos escolares. Esta mudança estaria correlacionada, segundo Oliveira (2011), a um processo de descentralização induzido pela Constituição Federal de 1988, que teria levado a uma ampliação considerável do número de atores políticos, favorecendo a emergência de movimentos de caráter identitários, de valorização da diversidade e o consequente aumento do espaço de negociação de políticas voltadas para seus interesses. Segundo Gomes (2011), o processo de desenvolvimento dessas políticas, ocorrido no Brasil, decorre de um processo ativo de lutas, nas quais tiveram protagonismo os coletivos sociais historicamente privados do gozo do direito à educação.

Ao analisar o contexto latino-americano, Fanfani (2004) afirma que a educação assiste a uma profusão do número de atores organizados. Ele alerta, no entanto, para os problemas de governabilidade que esse fenômeno estaria trazendo para os sistemas educativos na América Latina. Segundo ele, o aumento do número de protagonistas e a valorização da diversidade cultural teria como consequência a necessidade de instituir novas formas de se fazer política, armar coalisões e promover consensos provisórios, em suma, uma nova forma de conceber a participação política desses atores junto ao estado. Estas novas demandas estariam correlacionadas com a emergência de novos modelos de regulação da educação, em que o nível local aumenta sua responsabilidade na definição das políticas. Segundo Maroy (2011), estes são os modelos de gestão 
"pós-burocráticos", uma resposta à distribuição do poder mais descentralizada em que o local ganha primazia na condução das políticas, embora seu controle esteja centralizado em um estado avaliador, que realiza o acompanhamento à distância sobre os produtores e sobre os produtos dos seus sistemas educacionais.

Sintetizando,aemergênciadadiversidadecomoumareferênciaideológica importante na orientação das novas políticas educacionais tem sido acompanhada por uma relativa fragmentação do sistema educacional de tal modo que ele deixa de guiar-se, exclusivamente, pelos princípios do universalismo e atende demandas cada vez mais individualizadas. Este fenômeno tem se desenvolvido em uma relação de interdependência com a evolução das novas formas de regulação do sistema educacional, em que o controle sobre os processos e produtos da educação tem sido feito cada vez mais à distância, através de avaliações sistêmicas no final do processo, que avaliam o progresso de cada aluno através de provas estandartizadas. Este acoplamento potencializa ambos os processos tornando-se difícil propor, hoje, políticas de recomposição das desigualdades ou modos de regulação dos sistemas educativos que não se submetam a estes parâmetros.

\section{O trabalho docente e as políticas de acolhimento à diversidade}

São muitos os diagnósticos realizados sobre a escola e o trabalho que nela se realiza. A pesquisa "O Trabalho Docente na Educação Básica no Brasil" (OLIVEIRA; VIEIRA, 2010, 2013) ${ }^{7}$ é um deles. Esses diagnósticos mostram condições de trabalho, de salário e de carreira precárias. É, nesse contexto, que as novas políticas abertas para a diversidade trazem novos desafios. Uma agenda mais aberta à diversidade, no contexto de um sistema que exige uma performance escolar homogênea no final do processo, deixa em evidência as contradições do próprio sistema escolar. Embora haja no nível do discurso um grande consenso sobre o direito de todas as crianças à educação, sem serem discriminadas por sua origem, condição ou classe social, há também uma grande tensão, oriunda da tentativa de adequar equidade e performance em contextos sociais cada vez mais heterogêneos.

Nos deparamos com duas tendências em disputa, refletidas em dois projetos de sociedade que o sistema escolar deveria ajudar a construir. Uma tendência se alinha com procedimos baseados na hierarquização das capacidades individuais, baseadas no suposto mérito individual, verificado ao longo do percurso do aluno no sistema escolar; podemos chamá-la a tendência da "falta". Esta tendência está fortemente inscrita nos índices de avaliação, que procuram registrar a performance do sistema pela mensuração do desempenho dos alunos. Outra tendência é a de dar a cada um conforme suas necessidades, assumindo que somos todos diferentes e que a hierarquização que a escola institui não é desejável. A tensão entre ambas constitui importante carga sobre o trabalhador docente e, frequentemente, constitui-se em fonte de insatisfação no trabalho e sofrimento, conforme observamos na seguinte fala de uma professora durante a realização de um grupo focal para discutir o trabalho docente: 
eu posso ser uma excelente professora, posso fazer meus planos de aula brilhantes, mas se eu não tenho formação pra lidar com traficante, não tenho, eu não tenho formação pra lidar com menino que tem uma deficiência, que é surdo-mudo, ou muitas das vezes eu trabalhei com menina que era paraplégica, então quer dizer, é o sistema. Tudo bem, manda pra escola essa galera, pode mandar, mas que mande ter psicóloga pra trabalhar junto comigo, fonoaudióloga pra ajudar aquela galera, os meninos que estão vindo cumprir pena, porque agora é assim, qualquer briga, se você brigar na rua, se você tiver na festa e você cometer alguma, você vai cumprir pena na escola. É, brigou, banda, o cara tava lá na banda, brigou com não sei quem, o juiz determinou, você vai cumprir uma pena. Qual? Escola. (OLIVEIRA; VIEIRA, 2013)

A heterogeneidade dos interesses dos alunos, incrementadas pelas políticas de inclusão e acolhimento da diversidade, é vista como um almento da carga de trabalho por alguns professores. Eles por sua vez indicam a necessidade de que o sistema escolar preveja estratégias de acolhimento às demandas que eles não se sentem capazes de atender. Dentre estas estratégias estão a contratação de especialistas e a formação:

Agora, quando o sistema me coloca aquela diversidade de menino e fala que eu tenho que saber trabalhar com essa diversidade, ele está sendo cruel. Porque a diversidade a gente pode ter, por exemplo, cada um tem um tipo de pensamento, aí isso pra mim é diversidade, mas quando cada um tem um tipo de deficiência, isso pra mim já não é diversidade não, não é? Então eu vejo que é o sistema, então assim, eu no início do ano eu já vejo assim, olha, você vai trabalhar com qual turma? (OLIVEIRA; VIEIRA, 2013)

As duas falas reproduzidas aqui sugerem as marcas que as promessas de igualde em uma sociedade profundamente marcada pela desigualdade deixam nos trabalhadores docentes que procuram conciliá-las. A experiência de Rancière/ Jacotot, a experiência em sociedades indígenas relatadas por Bruno (2011) e as análises de Dubet apontam para o limite do ideal hegemônico de uma escola que seria justa porque promoveria a igualdade, pois este ideal se choca com o histórico compromisso do sistema educacional reproduzido e justificado pelas desigualdades sociais. Vivemos, portanto, o conflito da escola como promessa de reparação da igualdade e da escola como reprodução das desigualdades, enquanto afirmamos o ideal de promover a escola onde se afirma a igualdade na diversidade, um conflito que tem se dado essencialmente nas esferas de atribuição de sentido ao trabalho dos sujeitos docentes. 


\section{Referências}

BRASIL. Projeto de Lei n. 8035/2010. Aprova o Plano Nacional de Educação para o decênio 2011-2020 e dá outras providências. Brasília, 2010.

BRUNO, L. E. N. B. Gestão da educação escolar indígena diferenciada: contradições, limites e possibilidades. Revista Brasileira Estudos Pedagógicos. Brasília, v. 92, n. 232, p. 639-662, set./ dez. 2011.

DEMEUSE, M.; FRANDJI, D.; GREGER, D.; ROCHEX, J. (Orgs.). Les politiques d'éducation prioritaire en Europe: quel devenir pour l'égalité scolaire? Tome II. Lyon: ENS, 2011.

DINIZ-PEREIRA, J. E.; LEÃO, G., (Orgs.). Quando a diversidade interroga a formação docente. Belo Horizonte: Autêntica Editora, 2008.

DUBET, F. O que é uma escola justa? A escola das oportunidades. São Paulo: Cortez, 2008.

DUBET, F.; DURU-BELLAT, M.; VÉRÉTOUT, A. Les societes et leur école: emprise du diplôme et cohésion sociale. Paris: Seuil, 2010.

FANFANI, E. T. Nuevos problemas de gobierno de la educación en América Latina. Comentarios a las tesis de François Dubet. In: FANFANI, E. T. (Org.). Gobernabilidad de los sistemas educativos en América Latina. Buenos Aires: IIPE, 2004.

FRANDJI, D.; ROCHEX, J. F. Du devenir des politiques d'éducation prioritaire à la recheche des possibles. In: DEMEUSE, M, FRANDJI, D, GREGER, D. et ROCHEX, J. (Orgs.). Les politiques d'éducation prioriteire en Europe: quel devenir pour l'égalité scolaire? Tome II. Lyon: ENS, 2011.

FRASER, N. De redistribuição ao reconhecimento? Dilemas da justiça na era pós-socialista. In: SOUZA, J. (Org.). Democracia hoje: novos desafios para a teoria democrática contemporânea. Brasília: UNB, 2001.

GATTI, B.A.; BARRETO, E.S.; ANDRE, M.E.D.A. Políticas docentes no Brasil: um estado da arte. Brasília: Unesco, 2011.

GOMES, N.L. O Plano nacional de educação e a diversidade: dilemas, desafios e perspectivas. In: DOURADO, L.F. (Org.). Plano Nacional de Educação (2011-2020): avaliação e perspectivas. 2.ed. Goiânica: UFG, Belo Horizonte: Autêntica, 2011

MAROY, C. Em direção a uma regulação pós-burocrática dos sistemas de ensino na Europa? In: OLIVEIRA, D. A.; DUARTE, A. (Orgs.). Políticas públicas e educação: regulação e conhecimento. Belo Horizonte: Fino Traço, 2011.

MASSCHELEIN, M.; SIMONS, M. El odio a la educación pública. La escuela como marca de la democracia. In: SIMONS, M.; MASSCHELEIN, J.; LAROSSA, J. (Orgs.). Jacques Rancière: la educación pública y la domesticación de la democracia. Buenos Aires: Miño y Dávila, 2011.

MEC - Ministério da Educação. Conferencia Nacional de Educacao (CONAE). Documento Final: Construindo o Sistema Nacional Articulado de Educacao: o plano nacional de educação. Brasília, 2010.

MOEHLECKE, S. As Políticas de Diversidade na Educação no Governo Lula. Cadernos de Pesquisa, v. 39, n. 137, p. 461-487, maio/ago. 2009.

OLIVEIRA, D. A. Das políticas de governo à política de Estado: relexões sobre a atual agenda educacional brasileira. Educação e Sociedade, Campinas, v. 32, n. 115, p. 323-337, abr./jun. 2011. 
OLIVEIRA, D. A.; VIEIRA, L. M.F. Trabalho docente na educação básica no Brasil. Base de Dados TDEBB/GESTRADO. Faculdade de Educação/UFMG. Belo Horizonte, 2010. Apoio SEB/MEC.

OLIVEIRA, D. A.; VIEIRA, L. M. F. Trabalho docente na educação básica no Brasil. Base de Dados: transcrição dos grupos focais TDEBB/GESTRADO. Faculdade de Educação/ UFMG. Belo Horizonte. 2013. Apoio INEP.

RANCIĖRE, J. O mestre ignorante: cinco lições sobre a emancipação intelectual. Belo Horizonte: Autêntica, 2002.

Notas

1 O presente trabalho foi realizado com o apoio de bolsa PNPD/Capes. O artigo trata-se da versão revisada e ampliada do texto "Justiça, igualdade, atendimento à diversidade e as novas demandas para o trabalho docente", apresentado no IX Seminário da Red Estrado: Políticas Educativas na América Latina: Praxis Docente e Transformação Social. Santiago do Chile, 2012.

2 Índice criado pelo Intituto Nacional de Pesquisas Educacionais Anísio Teixeira em 2007, reunindo em um mesmo indicador medidas relacionadas ao fluxo escolar e média de desempenho nas avaliações, ligadas à qualidade da educação.

${ }^{3}$ Para Fraser (2001) reparar a injustiça que sofrem as mulheres, os negros, mas também grupos com sexualidades menosprezadas ou jovens em atraso escolar requer mudanças na cultura, ou seja, na forma de valorar socialmente as peculiaridades desses grupos, reconhecendo sua especificidade. Garantir seu direito à educação supõe, portanto, criar um espaço de reconhecimento e visibilidade social para estes grupos.

${ }^{4}$ Por exemplo, a discussão sobre a diversidade sexual, na escola, nos remete à homofobia que existe na sociedade, independentemente do sistema escolar, e interfere no direito à educação, seja porque a escola adota um currículo que veicula uma versão sobre a sexualidade humana que reforça estereótipos segregacionistas, seja porque o não reconhecimento cultural torna o ambiente escolar inóspito para estas pessoas. Raça e gênero também têm dimensões culturais-valorativas que ao longo do tempo vieram consolidando uma injustiça que se reflete também no nível sócio-econômico. No que tange a sua escolarização, negros e mulheres, por exemplo, são populações com maior nível de analfabetismo que a média, constinuindo-se em coletividades que ainda precisam lutar para valorizar-se em seus aspectos culturais, ao mesmo tempo que precisam encontrar caminhos para diminuir a diferenciação racial ou de gênero quando ela significa perda de oportunidades sócio-econômicas. Nesse sentido a escola aparece ainda, apesar de todas as contradições que apontamos, como um caminho privilegiado para a conquista desses direitos.

${ }^{5} \mathrm{O}$ nome completo do estudo é "Les politiques d'éducation prioritaire en Europe" e foi realizado por doze instituições de pesquisa em oito países europeus (Inglaterra, Bélgica, França, Portugal, Grécia, República Tcheca, Suécia e Romênia) entre 2006 e 2011, sob a coordenação do Institut Français de I'Éducation (IFÉ, ex Institut National de Recherche Pédagogique - INRP).

${ }^{6}$ Temos consciência que, embora haja uma certa convergência nas emergência das políticas ditas focalizadas no Brasil e na Europa, devemos tomar cuidado com as generalizações. Os processos de constituição dos sistemas nacionais de educação difere significativamente nos dois contextos, bem como suas características políticas e sociais. 
${ }^{7}$ A pesquisa o trabalho docente na educação básica no Brasil foi realizada entre 2009 e 2010 pelo Gestrado/UFMG com o objetivo de dar a conhecer "as condições de trabalho e o perfil dos trabalhadores da Educação Básica em escolas públicas municipais e estaduais, e instituições de educação infanti conveniadas com o poder público, em sete estados brasileiros, contemplando as cinco regiões: Pará, Rio Grande do Norte, Goiás, Espírito Santo, Minas Gerais, Paraná e Santa Catarina" (Gestrado, 2010, p. 14). A coleta de dados foi feita por meio de um "survey" em que participaram 428 escolas localizadas nas capitais e em outros quatro municípios nos sete estados. Ao todo foram entrevistados 8.770 sujeitos docentes, em uma amostra representativa de toda educação básica no Brasil, da educação infantil ao ensino médio.

* Professor Doutor da Universidade Federal de Minas Gerais, Faculdade de Educação.

\section{Correspondência}

Gustavo Bruno Bicalho Gonçalves - Universidade Federal de Minas Gerais, Faculdade de Educação. Av. Antônio Carlos, 6627, Pampulha, CEP: 31270-901 - Belo Horizonte, Minas Gerais - Brasil.

E-mail: gustavobrunobg@gmail.com

Recebido em 27 de fevereiro de 2013

Aprovado em 28 maio de 2013 
